\title{
Rollator related pedestrian single accidents and collision events in Sweden
}

\author{
Anna Carlsson ${ }^{1 *}$, Jörgen Lundälv ${ }^{2,3}$ \\ ${ }^{1}$ Chalmers Industrial Technology, Sweden \\ ${ }^{2}$ Department of Social Work, University of Gothenburg, Sweden \\ ${ }^{3}$ Department of Surgical and Perioperative Sciences, Umeå University, Sweden \\ *Corresponding author: anna.carlsson@chalmersindustriteknik.se
}

Handling editor: Aliaksei Laureshyn, Lund University, Sweden

Reviewers: Paul Schepers, Ministry of Infrastructure \& Water Management,

Rijkswaterstaat, Netherlands; Rob Methorst, Ministry of Infrastructure \& Water

Management, Rijkswaterstaat (retired), Netherlands

Received: 20 September 2021; Accepted: 3 January 2022; Published: 2 February 2022

\begin{abstract}
Rollators (four-wheel walkers in USA; zimmer frames in UK) are commonly used as mobility aids for the elderly and people with a variety of disabilities. Pedestrian rollator users are a sub-group of Vulnerable Road Users (VRUs), although this group is rarely recognised in traffic safety contexts. The aim of this study is to extract and analyse rollator related pedestrian accident and injury data in Sweden. The results will provide valuable insight into the risks and obstacles rollator users are exposed to in the traffic environment and may in the long term contribute to improving the mobility of this group. The current study is based on data from 2,020 accidents involving 2,305 persons extracted from the Swedish Traffic Accident Data Acquisition (STRADA) database. For consistency reasons, a subset of data $(\mathrm{N}=745)$ was analysed in order to investigate the development of accidents over a period of 10 years. Thereafter, each accident in the whole data set was registered as either single or collision. The results show that the number of rollator accidents in Sweden increased by approximately 80\% during 2007-2016. Females dominate the injury statistics of single accidents, collisions, as well as fatal outcome, which may be due to exposure and/or differences in physical characteristics. Single accidents are much more common than collisions $(n=1,668$ and $n=352$, respectively) and the injury consequences are at least as serious. Data from the present study have revealed that the frequency of minor injuries (ISS 1-3) is 4.3 times, moderate (ISS 4-8) 6.0 times and serious injuries (ISS 9-15) 8.9 times higher in single accidents than in collisions. Fatal injuries are, however, more common in collision events (33 in comparison to 8 ). The vast majority of single accidents (99\%) was due to falls. Many of the single accidents $(29 \%)$ were caused by ground level differences (typically a curb) or due to surface conditions (19\%). Collisions involved cars, trucks or buses in $91 \%$ of cases, occurring predominantly in car parks $(31 \%)$ and on (zebra) crossings (30\%). In 54\% of cases the vehicles reversed into the rollator. Abbreviated Injury Scale (AIS) 3+ injuries were dominated by head (36\%) and torso (33\%) injuries in collision events, and hip fractures $(71 \%)$ in single accidents. The present study shows that further research into rollator user related accidents, both single accidents and collision events, is required. In order to introduce appropriate measures, future work should follow up on accident and injury developments and further improve the quality of mobility aid related accident data in general. Improved stability and design, proper training programmes, effective maintenance services, development of a supporting infrastructure would contribute to increased safety for rollator users.
\end{abstract}

Keywords: acute injuries, elderly, rollators, traffic environment, vulnerable road users (VRUs), four-wheeled walkers 


\section{Introduction}

"Road safety is a challenge of epidemic proportions. With 1.25 million people killed on the world's roads each year and another 20-50 million seriously injured, road traffic injuries have become a public health priority whose social and economic implications extend well beyond the transport sector" (World Bank, 2017, page 6). The European Commission reported that 25,500 individuals died on European Union roads during 2016 and estimates that 135,000 suffered serious injuries (European Commission, Fact Sheet 2017). During 2019 in Sweden, out of a population of 10 million, 221 individuals were fatally injured and 3,850 seriously injured in accidents involving at least one 'moving vehicle' in the traffic environment (Swedish Transport Administration, 2020). Since 1997, traffic safety measures in Sweden have been based on what is commonly referred to as the Vision Zero charter, which has successfully contributed towards reducing the number of occupant fatalities in vehicles (The Government of Sweden, 1997; Johansson, 2009; Belin et al., 2012). A similar approach, frequently referred to as Sustainable Safety (SWOV, 2018) or the Safe System Approach (International Transport Forum, 2008), has been adopted by several other countries.

Vulnerable Road Users (VRUs) are defined in the Intelligent Transport Systems (ITS) Directive (2010, page 4) as "non-motorised road users, such as pedestrians and cyclists as well as motorcyclists and persons with disabilities or reduced mobility and orientation". According to the European Commission, VRU transport accounts for the same proportion of road fatalities as cars (46\%) (European Commission, Fact Sheet 2017). VRUs, such as pedestrians, cyclists and moped riders, for whom efforts in enhancing traffic safety is still facing major challenges, have steadily been attracting more attention (WHO, $2009 \& 2018$; Swedish Transport Administration $2017 \& 2018)$.

Pedestrians is a multifaceted sub-group of VRUs, involving all people in society ranging from children to the most fragile elderly. Traditionally, traffic safety has focused on avoiding or mitigating collision between pedestrians and other 'moving vehicles' (Elvik et al., 2009). However, pedestrian single accidents occurring in the traffic environment, of which the majority comprises fall accidents, is an immense and overlooked problem (Aldman et al., 1976; Nilsson, 1986; Öberg et al., 1996; Öberg, 2011; Berntman, 2015; Tournier et al., 2016; Methorst et al., 2017; Schepers, 2017; Aldred, 2018; Elvik \& Bjørnskau, 2019; Amin et al. 2022). This may partly be explained by the fact that since no vehicle is involved, pedestrian single accidents have not (yet) been included in the official definition of a road traffic accident (Swedish Transport Administration, 2020). However, earlier publications have argued that pedestrian single accidents should be included in the international definition of traffic accidents (Berg et al., 2016; Methorst et al., 2017).

In Sweden, pedestrian single accidents originating from the traffic environment (Swedish Transport Administration, 2020), averagely represent $45 \%$ of serious injuries (PMI 1\%+) and $34 \%$ of very serious injuries (PMI 10\%+, as defined by Malm et al., 2008). Thus, pedestrian single accidents represent the sole largest cause of injury in the traffic environment in Sweden. These single pedestrian accidents, mainly falls, can lead to disability, loss of independence, and fear of falling (Cruz et al., 2019). Age (elderly) and gender (females) are two important parameters affecting both risk of injury, as well as type and severity of the injury (Öberg, 2011). Öberg (2011) found that twice as many females than males were injured in single pedestrian 
accidents, which could not be explained by exposure data; the greatest difference was found in the age group $\geq 50$ years. Traffic safety strategies must consider that the growing elderly population (European Commission, 2018), whose physical condition is inherently different to that of younger adults (Aldred, 2018; Musselwhite, 2021), will in future need to use the traffic system to a greater extent.

Walking aids, such as rollators (four-wheel walkers, USA; zimmer frames, UK; see Figure A1 in Appendix), are commonly used by elderly pedestrians in the traffic environment. The rollator is a Swedish innovation developed as a training tool by the hospital social worker, Aina Wifalk, who did not patent her innovation because she wanted the rollator to be available to everyone (Råssjö, 2016). Since its introduction in 1981, when the first rollator was introduced on the market, it has been widely accepted. In Sweden, $40 \%$ of women and $20 \%$ of men use some form of walking aid at the age of 75; at 85 years the proportion increases to $70 \%$ and $55 \%$, respectively (The Swedish Handicap Institute, 2014). However, knowledge and awareness concerning acute rollator related accidents and injuries in the traffic environment are limited. Hence, the aims of this study were to analyse national rollator related accident and injury data reported to the Swedish Traffic Accident Data Acquisition (STRADA) database, in particular the development over a period of 10 years, and investigate crash circumstances as well as risk factors (by comparing with data for the general population, where applicable). The results will provide valuable insight into the risks and obstacles that rollator users are exposed to in the traffic environment and may also contribute to improving the mobility of this group in the long term. This knowledge may also contribute to Sweden achieving the goal of reducing the number of seriously injured road users by $25 \%$, including pedestrian single accidents, by 2030 (The Government of Sweden, 2020). This study relates to our previous study into powered mobility devices (Carlsson \& Lundälv, 2019).

\section{Methodology}

\subsection{Data collection - STRADA}

Relevant data from accidents/injuries involving rollator users were extracted from the Swedish Traffic Accident Data Acquisition (STRADA) database. The national information system, STRADA, contains data provided by the police and the national health service of traffic accidents and injuries sustained within the Swedish road transport system. To ensure data is comprehensive and as detailed as possible, any data entered in STRADA is derived from two separate sources: police reported traffic accident records and records provided by medical establishments/health care providers.

Including hospital records in the study enhances the understanding of the type, as well as the severity of injuries sustained. Furthermore, hospital data reduces the amount of unaccounted accidents and increases police insight into certain categories of road traffic accidents (in particular accidents involving VRUs such as pedestrians, cyclists and moped riders). Police records generally incorporate information not included in hospital reports, for instance, the exact circumstances and the environment in which a traffic accident occurred.

STRADA is administered by the Swedish Transport Agency. Early trials of the database were initiated in 1999, and reports have been received regularly by the police nationwide since 2003 . In 2003, STRADA obtained data from 29 hospitals, this figure has gradually increased to 68 hospitals in 2012 and 71 hospitals in 2016. 
Since the STRADA database lacks specific variables regarding walking aids, what is generally referred to as a 'free text search' was performed, in order to identify relevant cases. The keywords used for this search were 'rollator' plus synonyms. The search resulted in a total of 2,361 unique accident identities, i.e., respective accidents, involving 2,688 persons during the period 1 January 2000 to 31 May 2017.

\subsection{Data analysis}

Information from the 2,361 accident cases and 2,688 persons were systematically analysed using Excel in the four phases described below (Figure 1). The statistical study was limited to a simple descriptive analysis.

- The first phase involved removing data concerning 354 accidents/383 persons from the dataset, considered irrelevant for the scope of this study. Consequently, the current study is based on data from 2,020 accidents and 2,305 persons.

- The second phase involved performing a development analysis to investigate whether the annual number of accidents involving rollators is increasing, decreasing, or at a static level. Sweden is divided into 21 different hospital regions; each region began reporting to STRADA at different times between 2000 to 2016 (Figure 2). For consistency reasons, inclusion criteria for the development analysis stipulates that a hospital region must have been fully reporting to STRADA during the 10-year period 20072016, which qualified 10 hospital

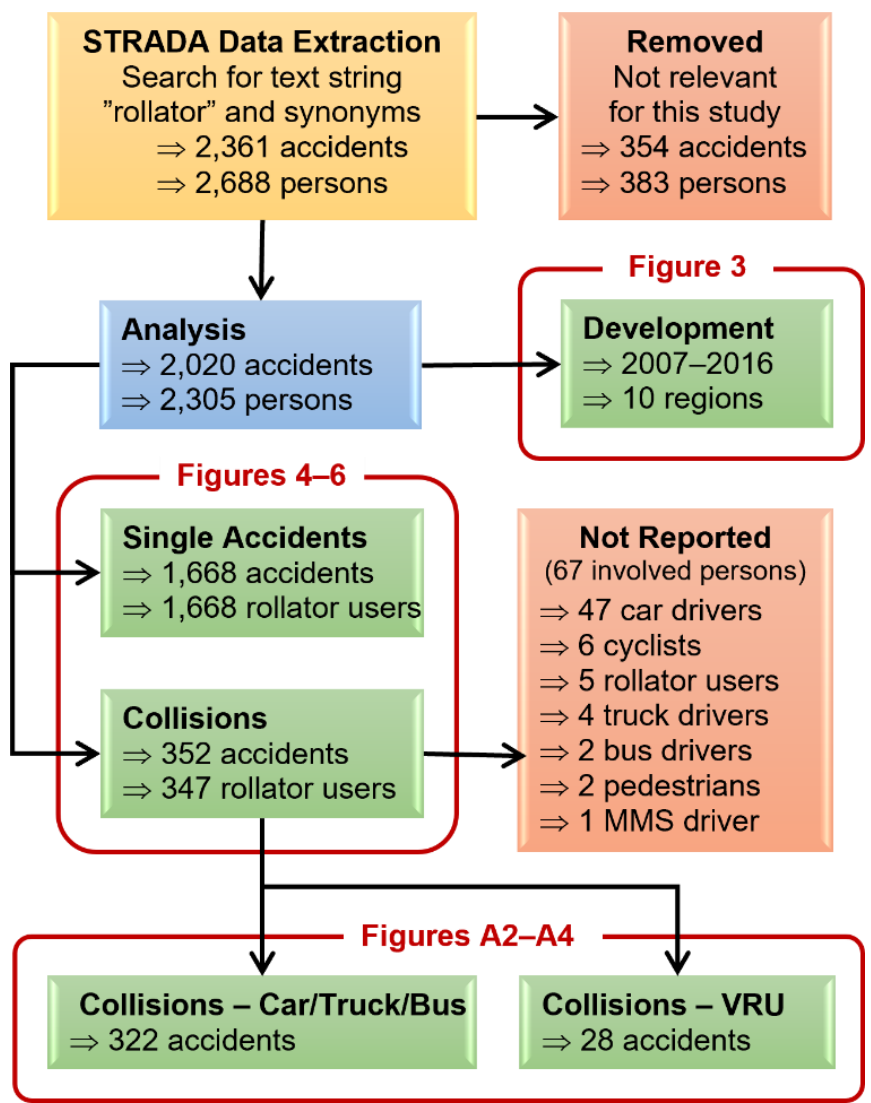

Figure 1. Schematic overview of performed data analysis regions and 745 accidents.

- The third phase involved registering each accident as either 'single' $(n=1,668)$ or 'collision' $(n=352)$, and categorising them based on text analysis of available information, in particular the accident description:

Single accidents were categorised as Fall (the rollator user impacted the ground) or Miscellaneous (sprained ancle, slipped and hit the rollator-Table 1). The circumstance of a single accident event was categorised as Curb, Trip, Stuck, i.e., the rollator got stuck, Surface, i.e., unevenness, poor maintenance, etc, Rolling away, i.e., the user was unable to keep up the speed with the rollator, Miscellaneous, and Unknown (Table 1). Examples of circumstances incorporated in the Miscellaneous category include 'knocked over by the 
wind', 'lost balance', 'pulled over by the dog', 'distraction', 'down-hill slope', 'heavily loaded rollator', and even 'aquaplaning' (in one case).

Collision events were categorised as Truck/Bus, Car, $M C / M o p e d / M M S \quad(\mathrm{MC}=$ Motorcycle; $\mathrm{MMS}=$ Motorised Mobility Scooter), Bicycle, Pedestrian or Miscellaneous (tourist train) (Table 1). The circumstance of an event was categorised as Zebra Crossing, Crossing, Road Section, Car park, F/C Lane (combined footpath and cycle lane), Footpath (including pavement), Entrance, or Miscellaneous (Table 1). Examples of circumstances incorporated in the Miscellaneous category included 'bus stop', 'railway station', 'square", 'petrol station', and 'amusement park'.

Both single accidents and collisions, injured body region, injury severity and other relevant parameters were categorised in accordance with Table 1. The Injury Severity Score (ISS) is defined as the sum of squares of the highest Abbreviated Injury Scale (AIS) score in each of the three most severely injured body regions, with one exception; the ISS score which is automatically computed as 75 for individuals sustaining an injury of AIS 6 severity (the maximum ISS possible) (MacKenzie, 1984; Stevenson et al., 2001). The injury severity was categorised as Uninjured, Minor (ISS 1-3), Moderate (ISS 4-8), Severe (ISS 9-), Fatal and Unknown, in accordance with the STRADA registry.

- The fourth phase included categorising collision events into VRU collisions $(\mathrm{n}=28)$, and collision with cars/trucks/buses $(\mathrm{n}=322)$.

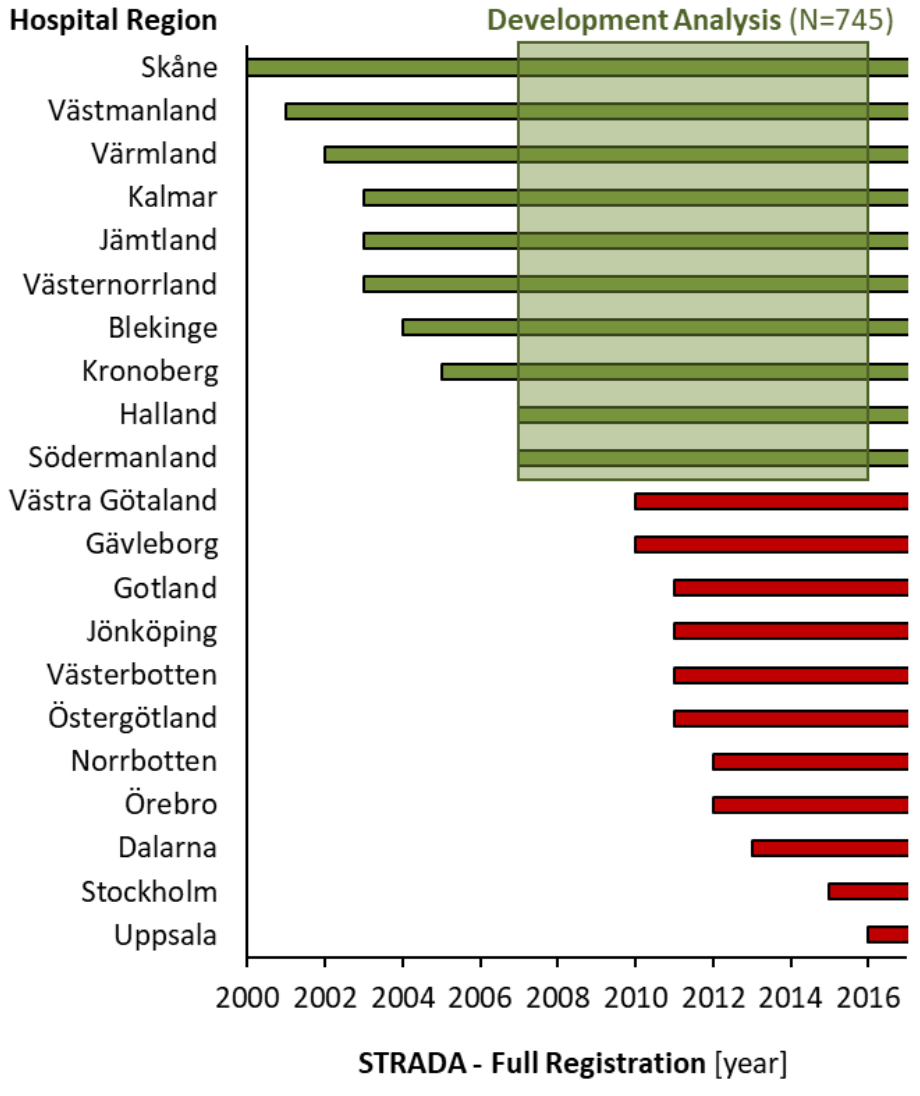

Figure 2. Hospital regions in Sweden including year they began reporting to STRADA. Green bars indicate that the region was used for the development analysis in the present study, covering the years 2007-2016. Red bars indicate that the region was excluded from the development analysis, since reporting to STRADA began after 2007. 
Table 1. Classification of accidents involving rollator users

\begin{tabular}{|c|c|c|}
\hline & Single & Collision \\
\hline$\underset{D}{\equiv}$ & $\begin{array}{l}\text { - Fall } \\
\text { - Miscellaneous }\end{array}$ & $\begin{array}{l}\text { - } \text { Truck/bus } \\
\text { - } \text { Car } \\
\text { - } M C / \text { moped/MMS } \\
\text { - Bicycle } \\
\text { - Pedestrian } \\
\text { - Miscellaneous }\end{array}$ \\
\hline 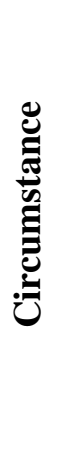 & $\begin{array}{l}\text { - Curb } \\
\text { - Trip } \\
\text { - Stuck } \\
\text { - Surface } \\
\text { - Rolling away } \\
\text { - Miscellaneous } \\
\text { - Unknown }\end{array}$ & $\begin{array}{l}\text { - Zebra crossing } \\
\text { - Crossing } \\
\text { - Road section } \\
\text { - Car park } \\
\text { - F/C lane } \\
\text { - Footpath } \\
\text { - Entrance } \\
\text { - Miscellaneous }\end{array}$ \\
\hline
\end{tabular}

\section{Single \& Collision}

- Head

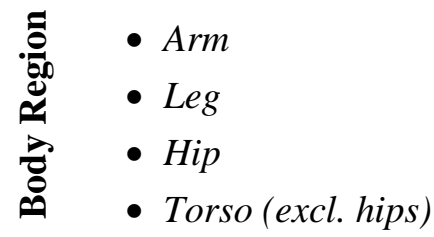

- Unknown

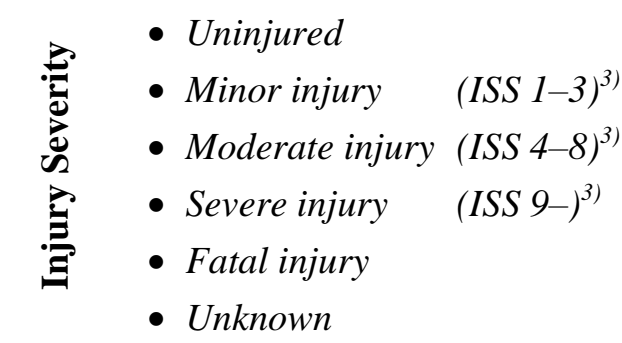

- Season

产

- Age

- Sex

1) Motorcycle (MC); Motorised Mobility Scooter (MMS)

2) Combined footpath and cycle lane (F/C lane)

3) Injury Severity Score (ISS) (MacKenzie 1984; Stevenson et al. 2001) 


\section{Results}

\subsection{0-year development}

Data was extracted for the development analysis from 10 hospital regions in Sweden for the period 2007-2016, as indicated in green in Figure 2. In total, 745 accidents were included, and their distribution has been depicted in a scatter plot (Figure 3). As seen in the plot, the rollator accidents increased by approximately $80 \%$ during 2007-2016.

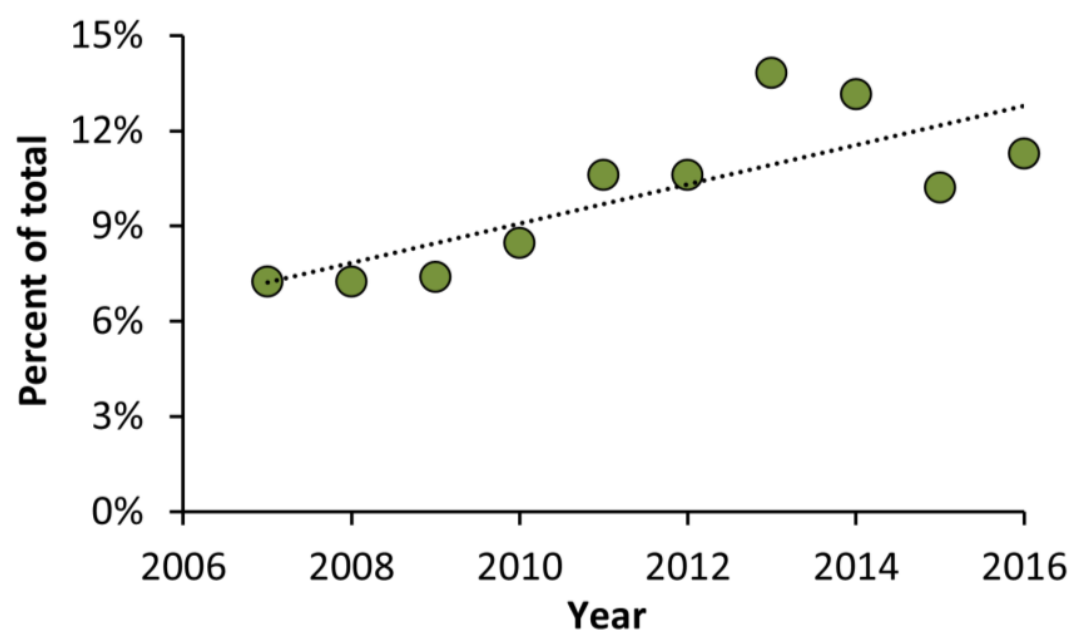

Figure 3. The number of rollator accidents increased between 2007-2016 (based on data from 10 hospital regions).

\subsection{Single accidents $(n=1,668)$}

The vast majority of single accidents (99\%) was due to falls (Figure 4a). These accidents were most often caused by a difference in ground level (typically a curb) (29\%), surface conditions (unevenness, poor maintenance, etc.) (19\%), trip (9\%), the rollator rolling away (7\%) or stuck (2\%) (Figure 4c).

Severe injury (ISS 9-) was registered in $18 \%$ of cases, moderate (ISS 4-8) 28\%, minor (ISS 13) $50 \%$, while $2 \%$ of cases remained uninjured (Figure $4 \mathrm{e}$ ). Fatal outcome was registered in eight cases $(0.5 \%)$, of which five involved females (mean age 88 years) and three involved males (mean age 85 years); in three of these cases the death was not caused by the accident. The body region most commonly injured in single accidents was the head (36\%), followed by upper limb/arm (27\%), hip (16\%), lower limb/leg (15\%), and torso (6\%) (Figure 5a). AIS 2+ injuries were most frequently situated in the arm (39\%), hip (33\%), and head (14\%) (Figure $5 \mathrm{c})$. AIS 3+ injuries were dominated by hip fractures (71\%) (Figure 5e).

\subsection{Collisions $(n=352)$}

The collision counterpart most often involved a car (77\%), followed by truck/bus (14\%), bicycle (4\%), MC/moped/motorised mobility scooter (MMS) (2\%) and pedestrian (2\%) (Figure 4b). Fatal injury was registered in $9 \%$ of cases; severe (ISS 9-) $10 \%$, moderate (ISS 4-8) $22 \%$, minor (ISS 1-3) 56\%, while 1\% of cases remained uninjured and $2 \%$ unknown (Figure 4f). Many of the accidents (29\%) occurred while crossing a road (21\% zebra crossing; $8 \%$ crossing) (Figure 4d). Pedestrians, cyclists, moped, MC or MMS drivers (VRUs) (n=28) (Figure A2a in Appendix) were most often involved in rollator collisions on footpaths (39\%), combined FC paths/bicycle lanes $(18 \%)$, road sections $(18 \%)$ or (zebra) crossings $(15 \%)$ (Figure A2c in Appendix). Cars, trucks and buses $(\mathrm{n}=322)$ (Figure A2b in Appendix) were most frequently 
involved in rollator collisions in car parks (31\%), on zebra crossings (22\%), crossings (8\%) or road sections (20\%) (Figure A2d in Appendix). In 54\% of cases, the vehicle reversed into the rollator.

In VRU collisions, $61 \%$ of the rollator users had sustained minor injuries, $18 \%$ moderate and $4 \%$ severe injuries, however, a large number remained unknown (18\%) (Figure A2e in Appendix). Limited information was available for the rollator users with regard to injured body region (36\% unknown) (Figures A3a,c in Appendix). Leg and arm injuries accounted for 15\%, respectively, followed by head (13\%), hip (10\%) and torso (10\%) (Figure A3a in Appendix). AIS 2+ injuries were dominated by arm injuries (50\%), followed by head, torso and hip (17\%, respectively) (Figure A3c in Appendix).

In car/truck/bus collisions, $55 \%$ of the rollator users had sustained minor injuries, $23 \%$ moderate, $10 \%$ severe, whereas 10\% represented fatal injuries (Figure A2f in Appendix). Of the 33 fatalities, 20 involved females (61\%) and 13 males (39\%), all were elderly (85 \pm 8 years old). Information regarding injured body region was missing in $22 \%$ of cases; the known cases were distributed over the head (24\%), arms (13\%), legs (19\%), hips (7\%) and torso (15\%) (Figure A3b in Appendix). AIS 2+ injuries were most frequently located to the head (26\%), torso (25\%), and leg (23\%) (Figure A3d in Appendix). AIS 3+ injuries were dominated by head (36\%) and torso (33\%) injuries (Figure A3e in Appendix).

Generally, the predominant reason for the missing information with regard to injury data was due to the accident only being recorded by the police, i.e., not by any hospital. In some cases, data were missing since only one of the collision partners was recorded in STRADA (see 'not reported' in Figure 1).

\subsection{Other Parameters}

Both single accidents and collision events were evenly distributed over the year (Figure 6a), however, VRU collisions were more common during the summer (Figure A4a in Appendix). Relatively few rollator collisions had occurred during weekends (especially Sundays), being more common during weekdays, whereas single accidents were more evenly distributed over the week (Figure 6b, A4b). Few rollator accidents occurred during late evenings or nights, occurring most frequently (82\%) during daytime between 10 am and $6 \mathrm{pm}$, peaking (25\%) between $2 \mathrm{pm}$ and $4 \mathrm{pm}$ (Figure 6c, A4c).

The analysis revealed that 2.4 times as many females (71\%) than males $(29 \%)$ were involved in rollator single accidents. In collisions, similar differences were found between female $(74 \%)$ and male $(25 \%)$ rollator users, however, gender was unknown in some cases $(1 \%)$, probably due to the VRU counterpart being injured, i.e., not the rollator user.

The average age of the rollator user was $82 \pm 9$ years (median 84 years) in collisions, and 81 \pm 10 years (median 83 years) in single accidents (Figure $6, \mathrm{~A} 4 \mathrm{~d}$ ). 
Single Accidents $(\mathrm{n}=1,668)$

Males / Females: $29 \% / 71 \%$

Accident events

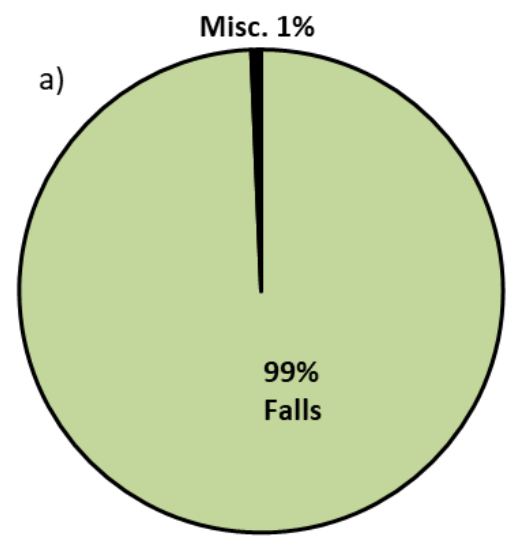

Accident Circumstance

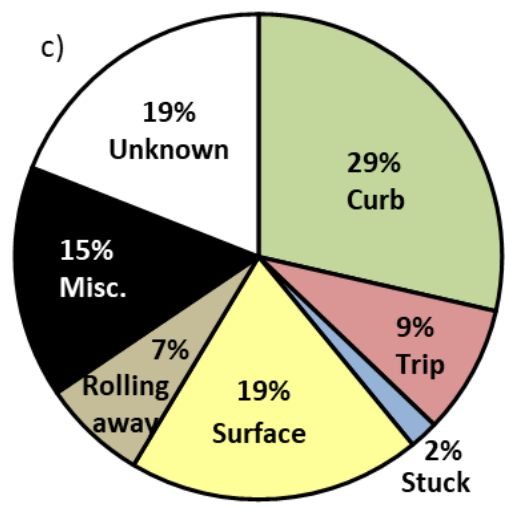

Injury Severity

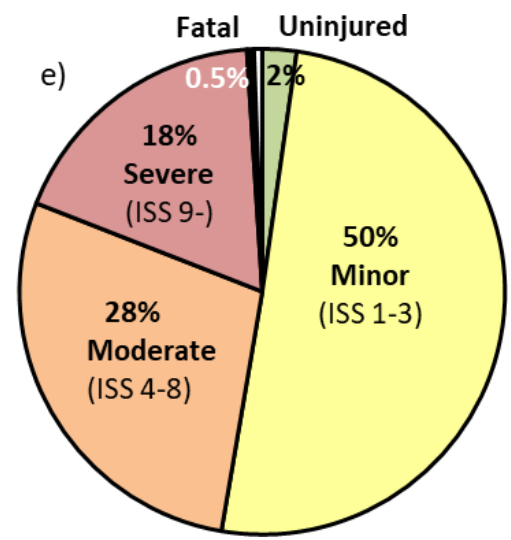

Collisions $(\mathrm{n}=352)$

Males / Females / Unknown: $25 \% / 74 \% / 1 \%$

Accident events

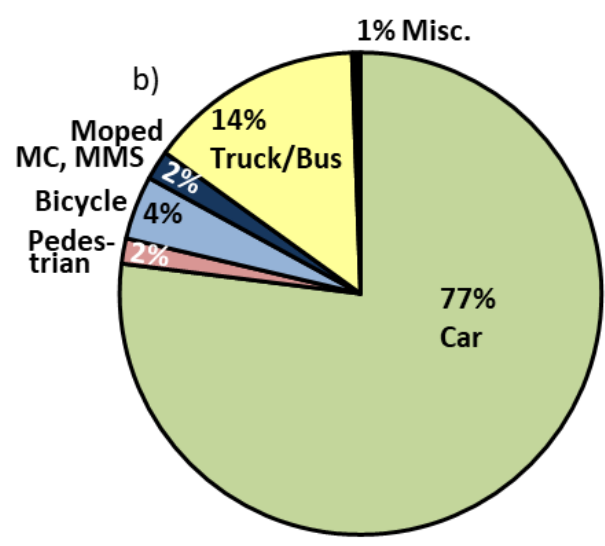

Accident Circumstance

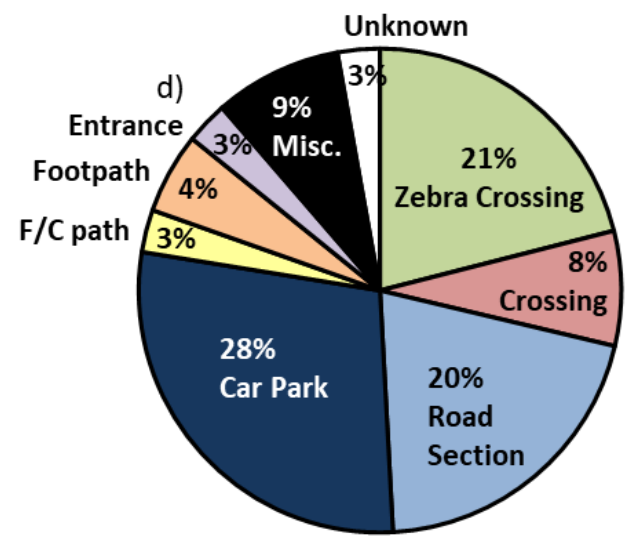

Injury Severity

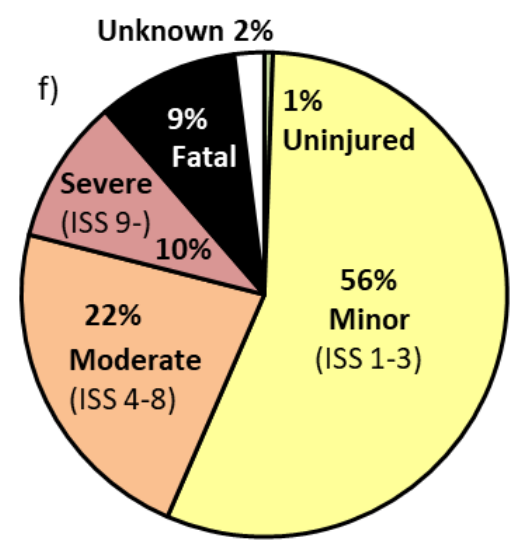

Figure 4. a) Single and b) collision accident events; c) single and d) collision accident circumstances; e) single and f) collision accidents injury severity 
Single Accidents $(\mathrm{n}=1,668)$

Males / Females: $29 \% / 71 \%$

All Reported Injuries $(\mathrm{n}=2,671)$

[5 cases unknown]

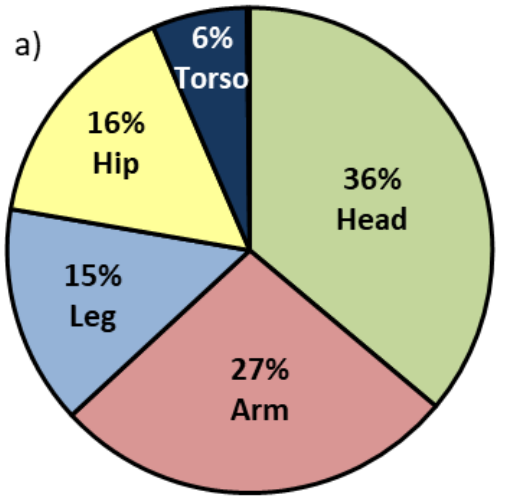

AIS 2+ Injuries ( $\mathrm{n}=926)$

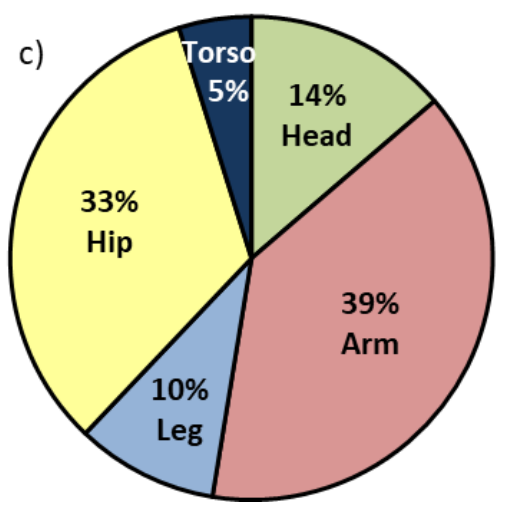

AIS 3+ Injuries ( $\mathrm{n}=322)$

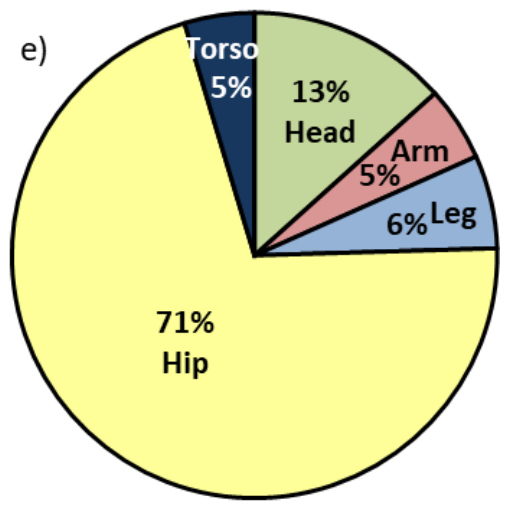

Collisions $(\mathrm{n}=352)$

Males / Females / Unknown: $25 \% / 74 \% / 1 \%$

\section{All Reported Injuries ( $\mathrm{n}=565)$}

[171 cases unknown]

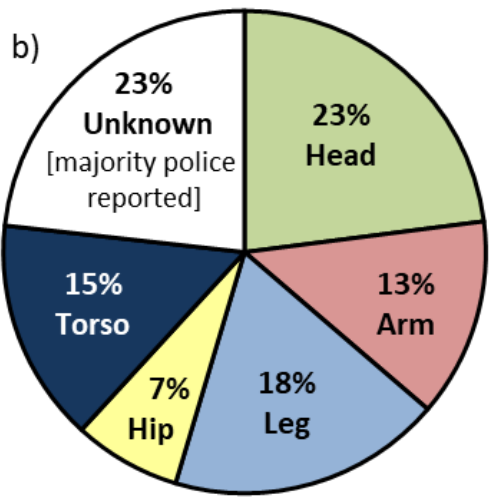

AIS 2+ Injuries ( $\mathrm{n}=292)$

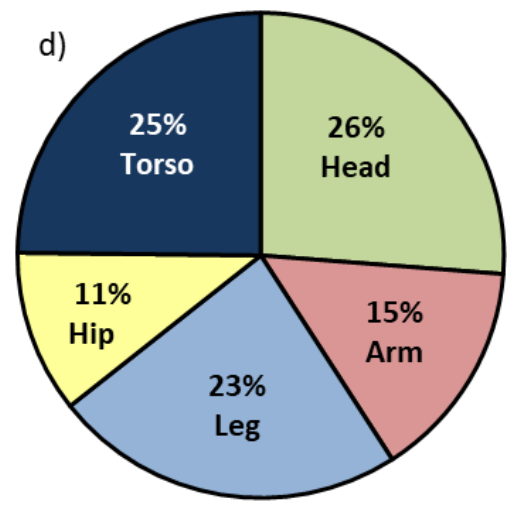

AIS 3+ Injuries ( $\mathrm{n}=135)$

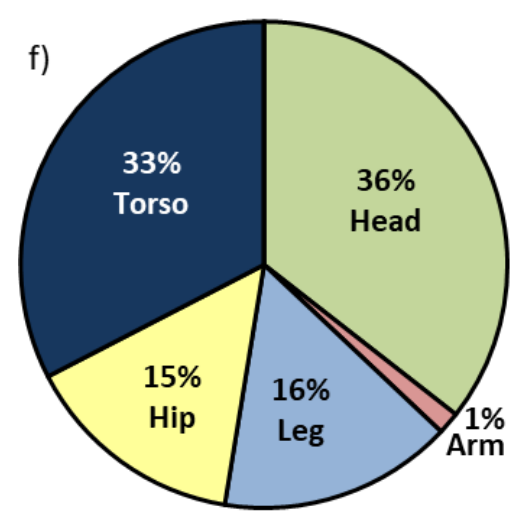

Figure 5. Injured body parts based on: all injuries in a) single and b) collision accidents; AIS 2+ injuries in c) single and d) collision accidents; AIS 3+ injuries in e) single and f) collision accidents 
a)

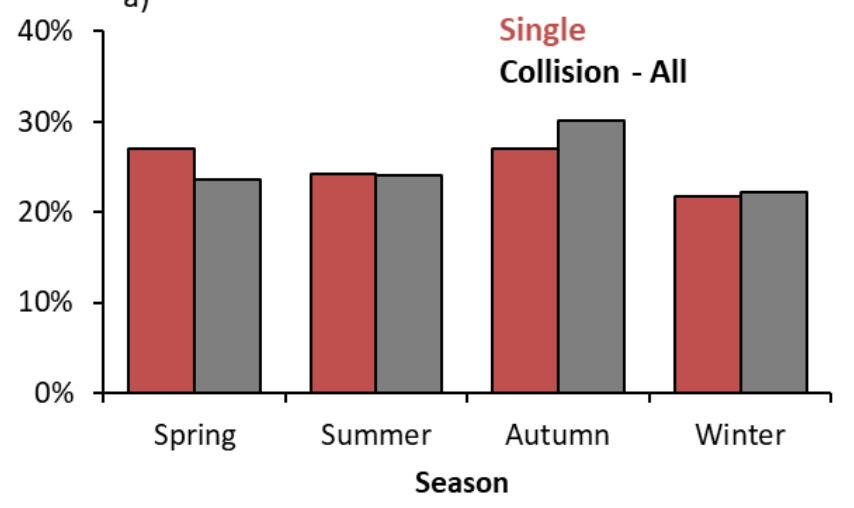

b)
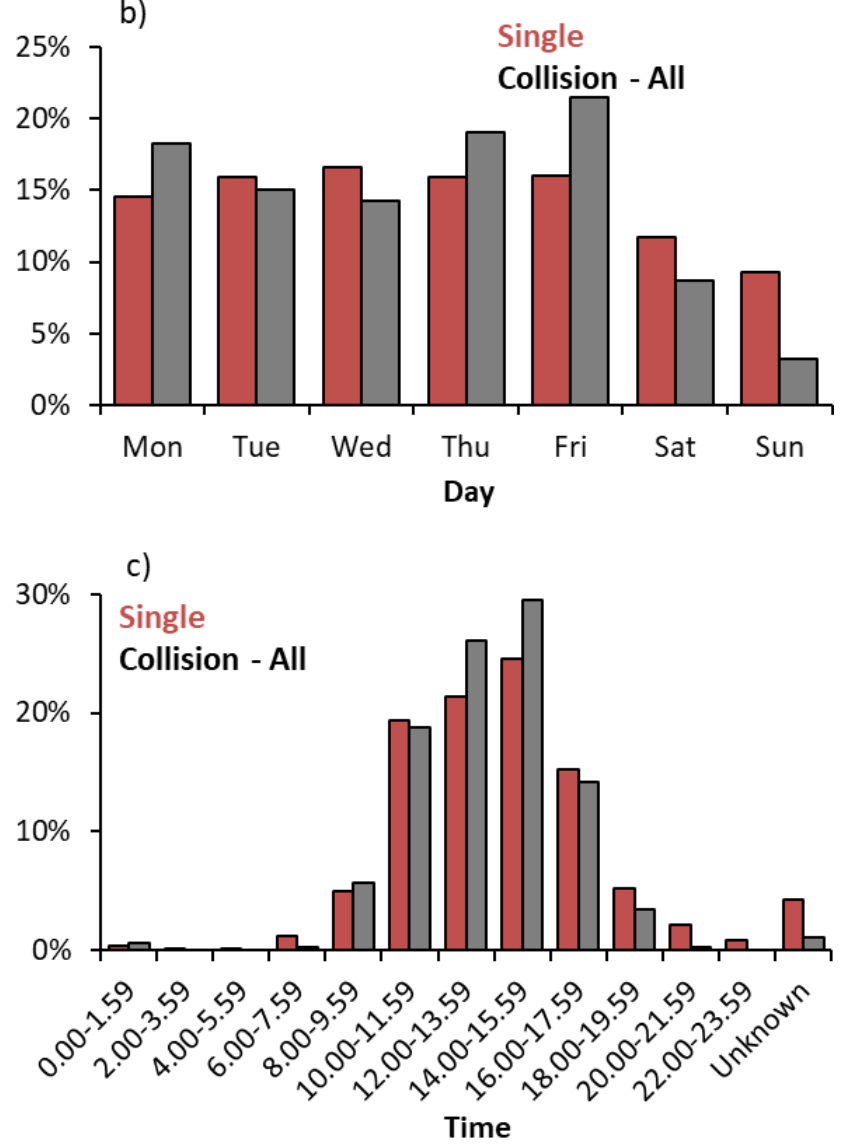

d)

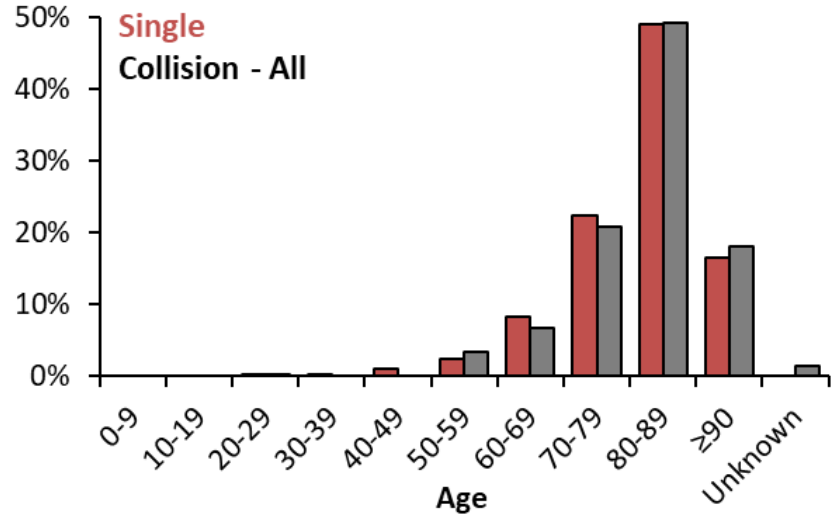

Figure 6. The distribution of a) season, b) day, c) time, and d) age of the driver in PMD single accidents (in red, $n=1,668$ ) and collisions (in grey, $n=352$ ) 


\section{Discussion}

Research into rollator users has traditionally been focused on usage, based on the ability of disabled individuals to manoeuvre a rollator and the significance of the mobility aid for everyday quality of life. The present study provides a new perspective based on national traffic accident data (STRADA) of acute traffic related injuries involving rollator users. This is in line with the Vision Zero charter, which was adopted by Sweden already 25 years ago (The Government of Sweden, 1997).

The results of this study reveal an increase in the number of rollator related accidents in Sweden (Figure 3). It is likely that the rising proportion of elderly members of society will contribute to a further increase in the number of rollator users, potentially continuing the escalation in rollator related accidents.

Single accidents among pedestrians are by definition not registered as road traffic accidents, since no vehicle is involved. Thus, these accidents are more or less invisible in traffic safety contexts. However, many pedestrians are seriously injured due to single accidents in the traffic environment. A recent study from Sweden found that the majority of fall related injuries occur outdoors (56\%, Ekbrand et al., 2020), which is in line with previous findings (Kelsey et al., 2012; Li et al. 2006, 2014). Data from the present study revealed that minor injuries (ISS 1-3) occur 4.3 times more often, moderate (ISS 4-8) 6.0 times and serious (ISS 9-15) 8.9 times more often, in single accidents than in collisions. Fatal injuries were however more common in collisions than in single accidents (33 and 8, respectively, by definition within 30 days from the injury event, Figure 4ef). Yet, hip fracture was the most dominant AIS 3+ injury among rollator users in single accidents (71\%, Figure 5e), somewhat higher than for pedestrians in general (68\% in Sweden, Carlsson \& Svensson, 2015). In Sweden, 15\% of women and 20\% of men die within four months after a hip fracture (Rikshöft, 2020). Thus, after four months from the injury event the number of fatalities related to single accidents may exceed those related to collisions. For the vast majority, walking is one (of several) means of transport, i.e., a chain of events, utilised to travel from one place to another, whereby each type of transport is associated with a certain accident risk (Aldman et al., 1976). From the "whole-journey" perspective, a bus trip may not be that safe if pedestrian single accidents en route to the bus stop would be accounted for (Aldman et al., 1976; Berntman et al., 2012). Thus, pedestrian single accidents should be included in the road traffic accident statistics.

Collisions occurred in $17 \%$ of rollator accidents, more than three times more in comparison to pedestrians in general (Sweden: 5\%, Carlsson \& Svensson, 2015). Furthermore, collisions involving motor vehicles (cars, trucks, buses) occurred most frequently while reversing (54\%), more than seven times more frequent in comparison to pedestrians in general (USA: 6.5\%, Stutts et al., 1996; France: 6.9\%, Brenac \& Fournier, 2018). These results confirm previous studies showing that older pedestrians are being overrepresented in reversing accidents (Dunbar et al., 2004; Brenac \& Fournier, 2018). Advancing age, and the inherent deterioration of the faculties such as hearing and vision, may be an influencing factor in elderly pedestrians failing to notice moving traffic (Dunbar et al., 2004). The elderly are also at an increased risk of being hit by a reversing vehicle due to cognitive abilities diminishing in relation to dementia related neuropathology (Gorrie et al., 2008). Foreseeing unpredictable reversing movements of vehicles in car parks can also be challenging for elderly pedestrians (Sheppard \& Pattinson, 1986). Lastly, their declining physical abilities may hinder their ability to move out of the way 
of a reversing vehicle fast enough to avoid being hit (Oxley \& Fildes, 1999; Dunbar et al., 2004; Charness et al., 2012). In collisions, head injury was the dominant AIS 3+ injury among rollator users (36\%), followed by torso (33\%), leg (16\%) and hip (15\%) injuries (Figure 5f). This differs from pedestrians in general, where hip/leg injury is the dominant AIS 3+ injury (36\%), followed by torso (36\%) and head (24\%) injuries (Berntman, 2015). The high frequency of reversing collisions among rollator users (54\%) may possibly contribute to these differences. It is thus important to study specific VRU groups separately in order to identify risk situations that otherwise might be missed. To address the problem with reversing accidents, the European New Car Assessment Programme (EuroNCAP), has introduced a new test scenario, the Autonomous Emergency Braking (AEB) Reverse, in which a pedestrian dummy is positioned behind a reversing car (EuroNCAP, 2020).

Gender differences are notable in the present study, females being involved in more than twice as many accidents than males, which may have several explanations. For example, a greater percentage of females than males use rollators (as well as walking sticks and wheelchairsGell et al., 2015). Furthermore, females are more likely to develop mobility limitations in advanced age (Gill et al., 2013) and are also at a greater risk of falling (Rosen et al., 2013). In addition, it is more common for females to experience a fear of falling (Peterson et al., 2017). However, some studies suggest that males are more prone to a adopt riskier behaviour (Gelbard et al., 2014). Consequently, much of the research has been focused on females (see for example Liu et al., 2015; Rosenberg et al., 2013), although suggestions for more research into fall accidents in males has been issued (Resnik et al., 2010).

Human factors are important to study due to rollator users representing a multifaceted, often slow-moving, subgroup of older pedestrians/VRUs, which may contribute to increased complexity in injury prevention strategies. The results of this study show that the average age of rollator users involved in accidents was above 80 years (Figure 6d, A4d). The high average age can be explained by the large proportion of the elderly in Sweden who use some form of walking aid (The Swedish Handicap Institute, 2014). Physiological ageing as well as not doing enough physical activity (disuse) will hamper the different functions required for balance (postural control-Sherrington \& Tiedemann, 2015). Balance may also be affected by certain medical diagnoses and pharmaceutical drugs, which may vary according to dosage, metabolism and interactions. Falls have been particularly associated to psychoactive medicines affecting mental processes, i.e., perception, consciousness, cognition as well as mood and emotions, Generally, physiotherapy will improve many of the affected functions (Sherrington \& Tiedemann, 2015). Elderly users of assistive devices generally experience balance and/or mobility problems, are frail, and thus at increased risk of falling and sustaining injuries in the event of a fall (West et al., 2015). Consequences of falling include a fear of falling, social isolation, functional restriction, depression, institutionalisation and hospitalisation (Cruz et al., 2019).

Vehicle factors, i.e., rollator factors, include the technical performance, function, and construction, such as brakes, mechanics, and wheels, as well as adjustments and stability. Rollators used both indoors and outdoors must be small and flexible enough to manoeuvre indoors, yet stable enough to be used outdoors. However, using the same rollator both indoors and outdoors may result in significant amounts of dirt, such as mud or slush being brought indoors if the outdoor surface is inadequate. Consequently, in some weather conditions users may avoid bringing their rollator outdoors, thereby impeding their mobility. One alternative is 
to use different rollators indoors (smaller, easily manoeuvred) and outdoors (robust with larger set of wheels), each tailored to the respective environment (Figure A1 in Appendix). However, further adjustments may be required to make a rollator suitable for outdoor use, such as visibility, lights, tyre size, slope brake function, mass distribution, stability, seating and secure storage arrangements. Transporting goods on a rollator while bringing the equipment over a curb is challenging for someone whose strength and/or balance is already compromised. A further factor that needs to be considered is that the private rollator market in countries such as Sweden is rather extensive, hence it remains unknown whether skills are satisfactory for adapting the rollator as well as providing suitable advice for users' personal needs.

Environmental factors can be challenging for older pedestrians as many experience problems in situations demanding effective cognitive processing, fast responses and quick actions (Oxley et al., 2004). To date, the following environments have been deemed hazardous: intersections, multi-laned roads, fast moving traffic, crossings not allowing enough time for slow walkers, as well as curbs, congested and/or poorly maintained/uneven footpaths/roads (Oxley et al., 2004; Rosenberg et al., 2013). Inadequate snow/ice clearance may severely restrict mobility and cause difficulties in the daily lives of people with disabilities (Carlsson \& Lundälv, 2019). The present study shows that single accidents and collision events were evenly distributed over the year (Figure 6a). These figures differ from pedestrians in general, who had been subject to almost twice as many accidents during the winter (Carlsson \& Svensson, 2015). A plausible explanation would be that rollator users avoid outdoor activities during winter, possibly due to difficulties manoeuvring the rollator in snowy/icy conditions or coldness. This may also explain why collisions involving VRUs most frequently occur during summer (Figure A4a), since this mode of transport is more common during the summer season (for example cycling-Transport Analysis, 2015). Differences in ground level, which may result in lifting and pushing the rollator in synchronicity with body movements, is a destabilising factor (Bateni \& Maki, 2005; Cruz et $a l ., 2019)$. The present study shows that almost $60 \%$ of single accidents were due to ground conditions (curb 29\%; trip 9\%; stuck 2\%; surface 19\%), while many of the collision events occurred while crossing a road (21\% zebra crossing; $8 \%$ crossing). Previous research has identified curbs as a major obstacle and cause of accidents for rollator users (Rosenberg et al., 2013; Jiraporn et al., 2018; Chippendale \& Lee, 2018). The question arises as to the design of pavements (with curbs), and if any alternatives for separating pedestrians from other road users, while simultaneously safeguarding effective drainage and guidance for the visually impaired, are available? Furthermore, surprisingly many collision events involving rollators occurred in car parks (29\%), which is two times more in comparison to pedestrians in general (Finland: 13\%-Malin et al., 2020). A contributing factor may be that drivers operating vehicles in car parks may lack awareness of elderly pedestrians with disabilities (Oxley et al., 1997; Rosenberg et al., 2013). However, with recent developments in the field of active safety, i.e., autonomous brakes, the risk of this type of collision will likely decrease (EuroNCAP, 2020). Another way to improve the mobility and independence among rollator users would be to facilitate availability of resting places and adequate light sources (Rosenberg et al., 2013). Poor lighting may aggravate depth perception, which may increase the risk of accidents and prevent people from going out after dark.

Social/System factors are important to consider in order to reduce the risk of accidents for this particular category of road users, i.e., persons with motor impairments. This may include activities for disabled VRUs, appropriate prescription by healthcare professionals, proper 
training programmes, and effective and adequate maintenance routines, as highlighted in previous studies (Liu, 2009; Charette et al., 2018; Carlsson \& Lundälv, 2019). Studies have established that the majority of rollator users $(61 \%$ - Liu, 2009) have either personally acquired their walking support equipment, or been helped by family or friends, rather than by a medical expert. However, selecting an unsuitable rollator or using it inaccurately may, beside the risk of falling, result in excessive energy consumption, damage to the joints through extra pressure and make walking unstable (Charette et al., 2018; Cruz et al., 2019). Any training provided must include different common tasks undertaken daily (Costamagna et al., 2019). "Training should take place within the activities the frail elderly person usually performs and within their known environment" (Skymne et al., 2012).

A limitation of this study is the lack of specific variables regarding rollators in the STRADA database; there is no unified way of categorising these walking aids. A 'free text search' was performed in order to identify relevant cases, hence, there is a risk that cases might have been overlooked due to different spelling or vocabulary in the database. In order to allow follow-up studies, more information is needed about the circumstances preceding falls, both to better understand the contributing risk factors and to develop specific and effective fall prevention strategies (Stevens et al., 2009). Thus, data regarding vehicle (rollator) and environmental factors should be included in the accident and injury registration (Berg et al., 2017; Carlsson \& Lundälv, 2019). Injury severity and costs for falls would then be distinguishable for different environments (Berg et al., 2017). Beside the lack of injury data, research into rollator users' experience of accidents and perceived risks in the traffic environment is also limited. In addition, enhancing the knowledge about travel patterns and exposure for rollator users, would be valuable.

The present study has shown that more in-depth research is needed into rollator related accidents, both with regard to single accidents and collision events. Future work should follow up accident and injury developments and further improve the quality of rollator related accident data in order to take appropriate action. Improved vehicle stability and design, increased usage of safety equipment, proper training programmes, effective maintenance services, development of a supporting infrastructure would all contribute to increased safety and mobility for rollator users.

\section{Conclusions}

- The number of accidents relating to rollator users in Sweden is increasing. Further increase is to be expected due to the aging population.

- Single accidents are more common than collision events, and the injuries are at least as serious. The vast majority of single accidents was due to falls.

- Collision events involving motorised vehicles were commonly due to reversing. A noticeably high proportion of collisions involving motor vehicles occurred in car parks and on (zebra) crossings.

- Females dominate the injury statistics in single accidents, collisions, as well as fatal outcome.

- AIS 3+ injuries were dominated by head and torso injuries in collision events, and hip fractures in single accidents. 


\section{CRediT contribution statement}

Anna Carlsson: Conceptualization, Methodology, Software, Validation, Formal Analysis, Investigation, Resources, Data Curation, Writing - Original Draft, Writing - Review \& Editing, Visualisation, Project administration, Funding acquisition. Jörgen Lundälv: Validation, Investigation, Resources, Writing - Original Draft, Writing - Review \& Editing, Visualisation.

\section{Declaration of competing interests}

The authors report no competing interests.

\section{Acknowledgements}

This study was funded by Skyltfonden (TRV 2016/86272), held in trust by the Swedish Transport Administration. The Swedish Transport Agency extracted the data from the Swedish Accident Data Acquistion (STRADA) database. The study has been reviewed and approved in 2016 by the Ethics Board in Gothenburg, Sweden (Dnr 048-15). Images of rollator models courtesy of Ingemar Larsson, Hjälpmedelscentralen, Västra Götalandsregionen, Sweden.

\section{References}

Aldman, B., Forsström, Å., \& Samuelsson, U. (1976) Commuting accidents in the Stockholm region 1971. Proceedings: IRCOBI Conference 7-8 September 1976; Amsterdam (The Netherlands). http://www.ircobi.org/wordpress/downloads/irc1976/pdf_files/1976_22.pdf (Acc. 20 January 2022)

Aldred, R. (2018) Inequalities in self-report road injury risk in Britain: A new analysis of National Travel Survey data, focusing on pedestrian injuries. Journal of Transport \& Health, 9, pp. 96-104. https://doi.org/10.1016/j.jth.2018.03.006

Amin, K., Skyving, M., Bonander, C., \& Nilsson, F. Fall- and collision related injuries among pedestrians in road traffic environment - A Swedish national register-based study. Journal of Safety Research, 2022 (accepted for publication).

Bateni, H., \& Maki, BE. (2005) Assistive devices for balance and mobility: benefits, demands, and adverse consequences. Archives of Physical Medicine and Rehabilitation, 86(1), pp. 134-145 https://doi.org/10.1016/j.apmr.2004.04.023

Belin, M-Å., Tillgren, P., \& Vedung, E. (2012) Vision Zero: a road safety policy innovation. International Journal of Injury Control and Safety Promotion, 19(2), pp. 171-179 https://doi.org/10.1080/17457300.2011.635213

Berg, GM., Carlson, T., Fairchild, J., Edwards, C., \& Sorell, R. (2017) Development of a Falls Registry: A Pilot Study. Journal of Trauma Nursing, 24(4), pp. 224-230 https://doi.org/10.1097/JTN.0000000000000295

Berg, HY., Ifver, J., \& Hasselberg, M. (2016) Public health consequences of road traffic injuries - Estimation of seriously injured persons based on risk for permanent medical impairment. Transportation Research Part F: Traffic Psychology and Behaviour, 38, pp. 1-6 https://doi.org/10.1016/j.trf.2015.12.007

Berntman, M., Holmberg, B., \& Wretstrand, A. (2012) Hur säker är bussen? Skador och risker i samband med bussresor i tätort. Bulletin 274, Department of Technology and Society, Lund University, Sweden.

Berntman, M. (2015) Fotgängares olyckor och skador i trafikmiljö med fokus på fallolyckor. Bulletin 295. Department of Technology and Society, Lund University, Sweden.

Brenac, T., \& Fournier, J-F. (2018) Collisions between pedestrians and reversing vehicles in public settings in France. The Open Transportation Journal, 12(1), pp. 33-42 https://doi.org/10.2174/1874447801812010033

Carlsson, A., \& Svensson, M. (2015) Fallolyckor Bland Gångtrafikanter. Report TRV 2013/71828. Chalmers Industriteknik, Gothenburg, Sweden. https://publications.lib.chalmers.se/records/fulltext/226311/local_226311.pdf(Acc. 20 January 2022)

Carlsson, A., \& Lundälv, J. (2019) Acute injuries resulting from accidents involving powered mobility devices (PMDs) - Development and outcomes of PMD-related accidents in Sweden. Traffic Injury Prevention, 20(5), pp. 484-491 https://doi.org/10.1080/15389588.2019.1606910 
Charette, C., Best, KL., Smith, EM., Miller, WC., \& Routhier, F. (2018) Walking Aid Use in Canada: Prevalence and Demographic Characteristics Among Community-Dwelling Users. Physical Therapy, 98(7), pp. 571-577 https://doi.org/10.1093/ptj/pzy038

Charness, N., Boot, W., Mitchum, A., Stothart, C., \& Lupton, H. (2012) Aging Driver and Pedestrian Safety: Parking Lot Hazards Study. Florida State University, Tallahassee, FL, Final Technical Report No. BDK83 977-1012.

Chippendale, T., \& Lee, CD. (2018) Characteristics and fall experiences of older adults with and without fear of falling outdoors. Ageing and Mental Health, 22(6), pp. 849-855 https://doi.org/10.1080/13607863.2017.1309639

Costamagna, E., Thies, SB., Kenney, LPJ., Howard, D., Lindemann, U., Klenk, J., \& Baker, R. (2019) Objective measures of rollator user stability and device loading during different walking scenarios. PLoS ONE, 14(1), pp. 1-13 https://doi.org/10.1371/journal.pone.0210960

Cruz, AO., Santana, SMM., Costa CM., Gomes da Costa, LV., \& Ferraz, DD. (2019) Prevalence of falls in frail elderly users of ambulatory assistive devices: a comparative study. Disability and Rehabilitation: Assistive Technology, 15(5), pp. 510-514 https://doi.org/10.1080/17483107.2019.1587016

Dunbar, G., Holland, CA., \& Maylor, EA. (2004) Older pedestrians: a critical review of the literature. Department for Transport, London, UK, Road Safety Research Rep. 37.

Ekbrand, H., Ekman, R., Thodelius, C., \& Möller, M. (2020) Fall-related injuries for three ages groups Analysis of Swedish registry data 1999-2013. Journal of Safety Research, 73, pp. 143-152 https://doi.org/10.1016/j.jsr.2020.02.016

Elvik, R., Høye, A., Vaa, T., \& Sørensen, M. (2009) The handbook of road safety measures. Bingley: Emerald.

Elvik, R., \& Bjørnskau, T. (2019) Risk of pedestrian falls in Oslo, Norway: Relation to age, gender and walking surface condition. Journal of Transport and Health,12, pp. 359-370 https://doi.org/10.1016/j.jth.2018.12.006

Elvik, R., \& Goel, R. (2019) Safety-in-numbers: An updated meta-analysis of estimates. Accident Analysis and Prevention, 129, pp. 136-147 https://doi.org/10.1016/j.aap.2019.05.019

EuroNCAP (2020) AEB Pedestrian www.euroncap.com/en/vehicle-safety/the-ratings-explained/vulnerableroad-user-vru-protection/aeb-pedestrian (Acc. 22 June 2020)

European Commission. (2017) - Fact Sheet. 2016 Road Safety Statistics: What is Behind the Figures? La Valette. https://ec.europa.eu/commission/presscorner/detail/en/MEMO_17_675 (Acc. 22 June 2020)

European Commission. (2018) The 2018 Ageing Report. Economic \& Budgetary Projections for the 28 EU Member States (2016-2070). Institutional Paper 079, May 2018. Luxembourg: Publications Office of the European Union https://ec.europa.eu/info/publications/economic-and-financial-affairs-publications_en (Acc. 22 June 2020)

Gelbard, R., Inaba, K., Okobye, OT., Morrell, M., Saadi, Z., Lam, L., Talving, P., \& Demetriades, D. (2014) Falls in the elderly: a modern look at an old problem. The American Journal of Surgery, 208(2), pp. 249253 https://doi.org/10.1016/j.amjsurg.2013.12.034

Gell, NM., Wallace, RB., LaCroix, AZ., Mroz, TM., \& Patel, KV. (2015) Mobility Device Use in Older Adults and Incidence of Falls and Worry About Falling: Findings from the 2011-2012 National Health and Aging Trends Study. Journal of the American Geriatrics Society, 63(5), pp. 853-859 http://doi.org/10.1111/jgs.13393

Gill, TM., Gahbauer, EA., Lin, H., Han, L., \& Allore, HG. (2013) Comparisons between older men and women in the trajectory and burden of disability over the course of nearly 14 years. Journal of the American Medical Directors Association, 14(4), pp. 280-286 http://doi.org/10.1016/j.jamda.2012.11.011

Gorrie, CA., Brown, J., \& Waite, PME. (2008) Crash characteristics of older pedestrian fatalities: Dementia pathology may be related to 'at risk' traffic situations. Accident Analysis and Prevention, 40(3), pp. 912-919 https://doi.org/10.1016/j.aap.2007.10.006

The Government of Sweden (1997) Bill 1996/97:137: Vision Zero and the Traffic Safety Society. Stockholm.

The Government of Sweden (2020) Excerpt from the minutes of the government meeting, 13 February; I2020/00423/US, I2019/00433/US.

International Transport Forum (2008) Towards Zero: Ambitious Road Safety Targets and the Safe System Approach, OECD Publishing, Paris https://doi.org/10.1787/9789282101964-en

Intelligent Transport Systems (ITS) Directive. (2010) For the deployment of Intelligent Transport Systems in the field of road transport and for interfaces with other modes of transport. Directive 2010/40/EU of the European Parliament and of the Council of 7 July 2010, Official Journal of the European Union. Article 4 Definitions No. 7. http://eur-lex.europa.eu/legal-content/EN/TXT/PDF/? uri1/4CELEX:32010L0040\&from1/4EN (Acc. 20 January 2022) 
Jiraporn, S-O., Tirrell, GP., Kamsom, A., Marill, KA., Shankar, KN., \& Liu, SW. (2018) A High-yield Fall Risk and Adverse Events Screening Questions From the Stopping Elderly Accidents, Death, and Injuries (STEADI) Guideline for Older Emergency Department Fall Patients. Academic Emergency Medicine: Official Journal of the Society for Academic Emergency Medicine, 25(8), pp. 927-938 https://doi.org/10.1111/acem.13413

Johansson, R. (2009) Vision Zero - Implementing a policy for traffic safety. Safety Science, 47(6), pp. 826-831 https://doi.org/10.1016/j.ssci.2008.10.023

Kelsey, JL., Procter-Gray,. E, Hannan, M T., \& Li, W. (2012) Heterogeneity of Falls Among Older Adults: Implications for Public Health Prevention. American Journal of Public Health, 102(11), pp. 2149-2156 https://doi.org/10.2105/AJPH.2012.300677

Li, W., Keegan, TH., Sternfeld, B., Sidney, S., Quesenberry, CP., \& Jr Kelsey, JL. (2006) Outdoor falls among middle-aged and older adults: A neglected public health problem. American Journal of Public Health, 96(7), pp. 1192-1200 https://doi.org/10.2105/AJPH.2005.083055

Li, W., Procter-Gray, E., Lipsitz, LA., Leveille, SG., Hackman, H., Biondolillo, M., \& Hannan, MT. (2014) Utilitarian walking, neighborhood environment, and risk of outdoor falls among older adults. Amerian Journal of Public Health, 104(9), pp. e30-37 https://doi.org/10.2105/AJPH.2014.302104

Liu, HH. (2009) Assessment of rolling walkers used by older adults in senior-living communities. Geriatrics \& Gerontology International, 9(2), pp. 124-130 https://doi.org/10.1111/j.1447-0594.2008.00497.x

MacKenzie, EJ. (1984) Injury severity scales: overview and directions for future research. American Journal of Emergency Medicine, 2(6), pp. 537-549 https://doi.org/10.1016/0735-6757(84)90081-0

Malin, F., Silla, A., \& Mladenović, M. (2020) Prevalence and factors associated with pedestrian fatalities and serious injuries: case Finland. European Transport Research Review, 12(29), pp. 1-17 https://doi.org/10.1186/s12544-020-00411-z

Malm, S., Krafft, M., Kullgren, A., Ydenius, A., \& Tingvall, C. (2008) Risk of permanent medical impairment (RPMI) in road traffic accidents. Annals of Advances in Automotive Medicine, 52, pp. 93-100.

Methorst, R., Schepers, P., Christie, N., Dijst, M., Risser, R., Sauter, D., \& van Wee, B. (2017) 'Pedestrian falls' as necessary addition to the current definition of traffic crashes for improved public health policies. Journal of Transport \& Health 6, pp. 10-12 https://doi.org/10.1016/j.jth.2017.02.005

Nilsson, G. (1986) Halkolyckor - Förekomst och konsekvenser. Report 291, Swedish National Road and Transport Research Institute (VTI), Linköping, Sweden

https://www.diva-portal.org/smash/get/diva2:674654/FULLTEXT01.pdf (Acc. 20 January 2022)

Oxley, JA., Fildes, BN., Ihsen, E., Charlton, JL., \& Day, RH. (1997) Differences in traffic judgements between young and old adult pedestrians. Accident Analysis and Prevention, 29(6), pp. 839-847 https://doi.org/10.1016/s0001-4575(97)00053-5

Oxley, J., \& Fildes, B. (1999) Safety of older pedestrians: strategy for future research and action initiatives. Monash University Accident Research Centre, Clayton, Victoria, Australia, Rep. 157 https://www.monash.edu/_data/assets/pdf_file/0007/216880/muarc157.pdf(Acc. 20 January 2022)

Oxley, JA., Corben, BF., Fildes, BN., \& Charlton, JL. (2004) Older pedestrians - meeting their safety and mobility needs. In J. Doak (Ed.), Proceedings of the 2004 Road Safety Research, Policing and Education Conference, 1, pp. 1-11. WA Office of Road Safety https://acrs.org.au/files/arsrpe/RS040052.pdf (Acc. 20 January 2022)

Peterson, LJ., Meng, H., Dobbs, D., \& Hyer, K. (2017) Gender Differences in Mobility Device Use Among U.S. Older Adults. The Journals of Gerontology. Series B, Psychological sciences and social sciences, 72(5), pp. 827-835 https://doi.org/10.1093/geronb/gbw081

Resnik, L., Allen, S., Isenstadt, D., Wasserman, M., \& Iezzoni, L. (2009) Perspectives on Use of Mobility Aids in a Diverse Population of Seniors: Implications for Intervention. Disability and Health Journal, 2(2), pp. 77-85 https://doi.org/10.1016/j.dhjo.2008.12.002

Rikshöft. (2020) Årsrapport 2020. RIKSHÖFT, Ortopediska kliniken, Skånes Universitetssjukhus Lund, Sweden.

Rosen, T., Mack, KA., \& Noonan, RK. (2013) Slipping and tripping: fall injuries in adults associated with rugs and carpets. Journal of Injury and Violence Research, 5(1), pp. 61-69 https://doi.org/10.5249/jivr.v5i1.177

Rosenberg, DE., Huang, S., Simonovich, SD., \& Belza, B. (2013) Outdoor Built Environment Barriers and Facilitators to Activity Among Midlife and Older Adults with Mobility Disabilities. Gerontologist, 53(2), pp. 268-279 https://doi.org/10.1093/geront/gns119

Råssjö, P. (2016) Rollatorn ger många äldre ett rörligare liv. Nerikes Allehanda. 24 September. 
Schepers, P., den Brinker, B., Methorst, R., \& Helbich, M. (2017) Pedestrian falls: A review of the literature and future research directions. Journal of Safety Research, 62, pp. 227-234

https://doi.org/10.1016/j.jsr.2017.06.020

Sheppard, D., \& Pattinson, MI. (1986) Interviews with elderly pedestrians involved in road accidents. Transport and Road Research Laboratory, Crowthorne, UK, TRRL Research Rep. 98.

Sherrington, C., \& Tiedemann, A. (2015) Physiotherapy in the prevention of falls in older people. Journal of Physiotherapy, 61(2), pp. 54-60 https://doi.org/10.1016/j.jphys.2015.02.011

Skymne, C., Dahlin-Ivanoff, S., Claesson, L., \& Eklund, K. (2012) Getting used to assistive devices: Ambivalent experiences by frail elderly persons. Scandinavian Journal of Occupational Therapy, 19(2), pp. 194-203 https://doi.org/10.3109/11038128.2011.569757

Stevens, JA., Thomas, K., the L., \& Greenspan, AI. (2009) Unintentional fall injuries associated with walkers and canes in older adults treated in U.S. emergency departments. Journal of the American Geriatrics Society, Aug;57(8), pp. 1464-1469 https://doi.org/10.1111/j.1532-5415.2009.02365.x

Stevenson, M., Segui-Gomez, M., Lescohier, I., Di Scala, C., \& McDonald-Smith, G. (2001) An overview of the Injury Severity Score and the New Injury Severity Score. Injury Prevention, 7(1), pp. 10-13 https://doi.org/10.1136/ip.7.1.10

Stutts, JC., Hunter, WW., \& Pein, WE. (1996) Pedestrian Crash Types: 1990s Update. Transportation Research Record: Journal of the Transportation Research Board, 1538, pp. 68-74 https://doi.org/10.1177/0361198196153800109

SWOV (2018) Sustainable Safety 3rd edition - The advanced vision for 2018-2030. Principles for design and organization of a casualty-free road traffic system. Report. The Hague: SWOV Institute for Road Safety Research. https://www.swov.nl/en/publication/sustainable-safety-3rd-edition-advanced-vision-2018-2030 (Acc. 20 January 2022)

The Swedish Handicap Institute. (2014) Äldrestatistik 2013/2014 - Sammanställning. The Swedish Handicap Institute. www.anhoriga.se/Global/Nyheter/Nyhetsdokument\%202014/14309-pdf-aldrestatistik-20132014.pdf (Acc. 20 January 2022)

The Swedish Transport Administration. (2017) Gemensam inriktning för säker gångtrafik 1.0. Report No. 2017:102. Borlänge, Sweden. https://trafikverket.ineko.se/Files/sv-

SE/26961/Ineko.Product.RelatedFiles/2017_102_gemensam_inriktning_for_saker_gangtrafik.pdf (Acc. 20 January 2022)

The Swedish Transport Administration. (2018) Gemensam inriktning för säker trafik med cykel och moped 2018. Report No. 2018:159. Borlänge, Swedenhttps://trafikverket.ineko.se/ Files/enUS/48193/Ineko.Product.RelatedFiles/2018_159_gemensam_ inriktning_for_saker_trafik_med_cyker_och_moped_2018.pdf (Acc. 20 January 2022)

The Swedish Transport Administration. (2020) Analys av trafiksäkerhetsutvecklingen 2019 - Målstyrning av trafiksäkerhetsarbetet mot etappmålen 2020. Report No. 2020:120. Borlänge, Sweden.

https://trafikverket.ineko.se/Files/sv-

SE/75691/Ineko.Product.RelatedFiles/2020_120_analys_av_trafiksakerhetsutvecklingen_2019_malstyrning. $p d f$ (Acc. 20 January 2022)

Tournier, I., Dommes, A., \& Cavallo, V. (2016) Review of safety and mobility issues among older pedestrians. Accident Analysis and Prevention, 91, pp. 24-35 https://doi.org/10.1016/j.aap.2016.02.031

Transport Analysis. (2015) Cyklandets utveckling i Sverige 1995-2014 - en analys av de nationella resvaneundersökningarna. Report 2015:14, Trafikanalys, Stockholm, Sweden.

https://www.trafa.se/globalassets/rapporter/2010-2015/2015/rapport-2015_14-cyklandets-utveckling-isverige-1995-2014.pdf (Acc. 20 January 2022)

West, BA., Bhat, G., Stevens, J., \& Bergen, G. (2015) Assistive device use and mobility-related factors among adults aged $\geq 65$ years. Journal of Safety Research, 55, pp. 147-150 https://doi.org/10.1016/j.jsr.2015.08.010

World Bank. (2017) The High Toll of Traffic Injuries: Unacceptable and Preventable - The Macro-Economic and Welfare Benefits of Reducing Road Traffic Injuries in Low- \& Middle-Income Countries. https://openknowledge.worldbank.org/handle/10986/29129 (Acc. 20 January 2022)

WHO (2009) Global status report on road safety: time for action. Geneva, World Health Organization https://www.afro.who.int/publications/global-status-report-road-safety-time-action (Acc. 20 January 2022)

WHO (2018) Global status report on road safety 2018. Geneva: World Health Organization. Licence: CC BYNC-SA 3.0 IGO https://www.who.int/publications/i/item/9789241565684 (Acc. 20 January 2022)

Öberg, G., Nilsson, G., Velin, H., Wretling, P., Berntman, M., Brundell-Freij, K., Hydén, C., \& Ståhl, A. (1996) Fotgängares och cyklisters singelolyckor. Report 799, Swedish National Road and Transport Research 
Institute (VTI), Linköping, Sweden http://vti.diva-portal.org/smash/get/diva2:672671/FULLTEXT01.pdf (Acc. 20 January 2022)

Öberg, G. (2011) Skadade fotgängare. Fokus på drift och underhåll vid analys av sjukvårdsregistrerade skadade i STRADA, Report 705, Swedish National Road and Transport Research Institute (VTI), Linköping, Sweden https://www.diva-portal.org/smash/get/diva2:670581/FULLTEXT01.pdf (Acc. 20 January 2022)

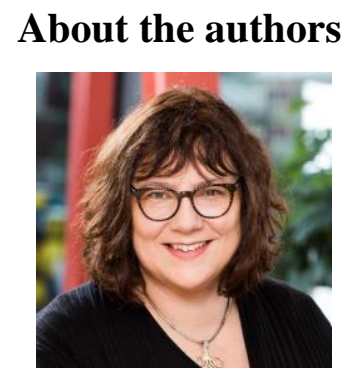

Anna Carlsson has more than 20 years of experience in Biomechanics and Injury Prevention within the area of Traffic Safety, with a special focus on women and the elderly, people with reduced mobility and vulnerable road users. She has one Master's Degree in Engineering Physics and one in Education, as well as a PhD in Machine and Vehicle Systems. Furthermore, Anna has experience of working in academia as well as in industry.

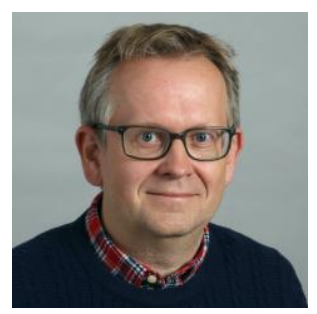

Jörgen Lundälv is Associated Professor in Traffic Medicine at the Department of Surgical and Perioperative Science, Umea University in Sweden. $\mathrm{He}$ is also Associate Professor in Social Work at the Department of Social Work, University of Gothenburg in Sweden. His research interests include traffic injuries, traffic safety, social policy, disability policy, social work, social exclusion, accessibility, inclusive research and injury research. He holds a $\mathrm{PhD}$ in social policy from the Department of Social Policy at the University of Helsinki, 1998 (Helsinki, Finland).

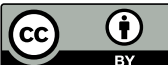

All contents are licensed under the Creative Commons Attribution 4.0 International License. 


\section{APPENDIX}
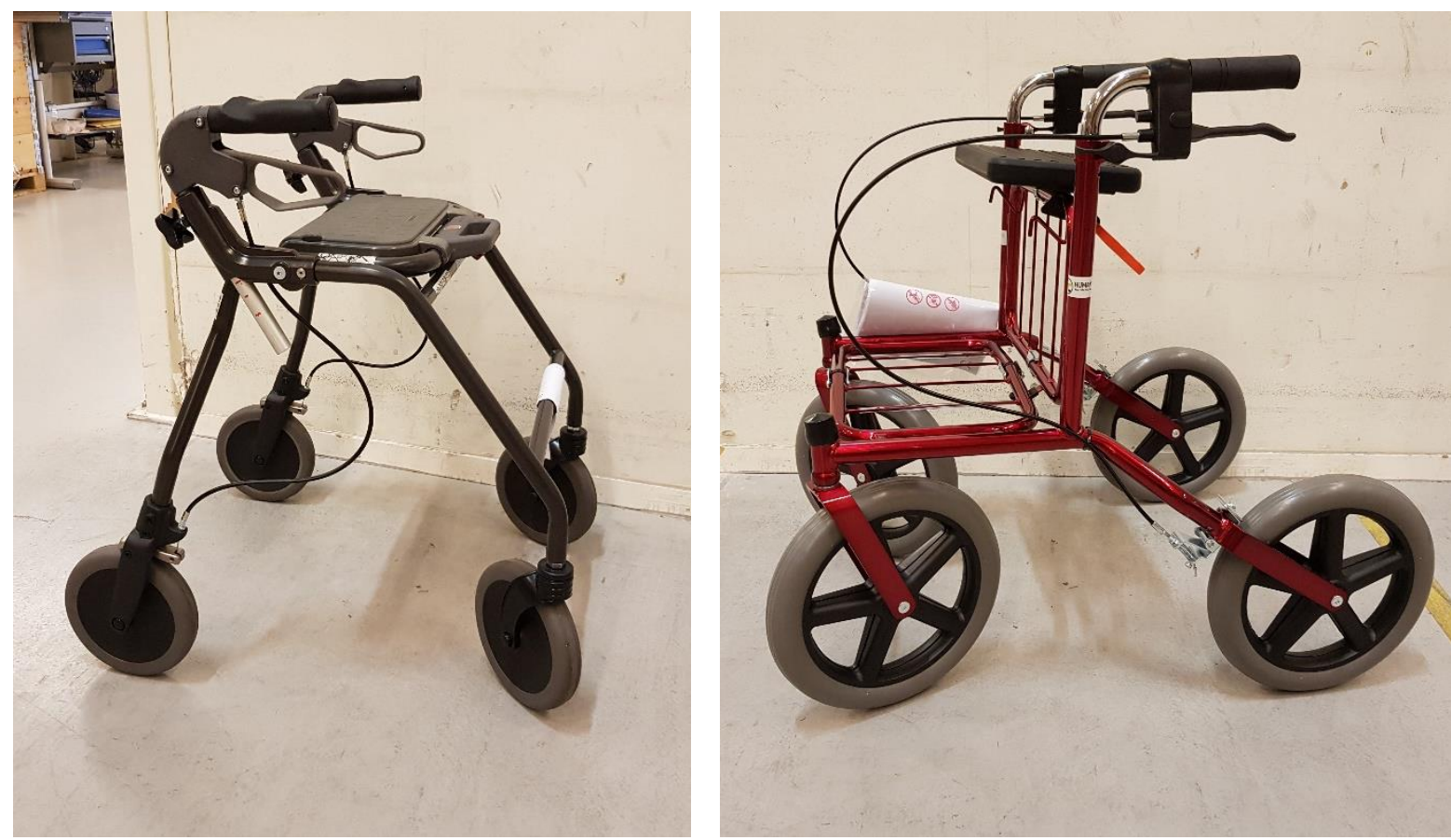

Figure A1. a) Indoor rollator (Futura 600) also suitable for outdoor use on even surfaces. b) Outdoor rollator (Carl-Oskar 62) suitable for both terrain and paved surfaces. Both rollators are of model year 2020. Photos: Ingemar Larsson, Hjälpmedelscentralen, Västra Götalandsregionen, Sweden. 
Collisions - VRU ( $\mathrm{n}=28)$

Males / Females / Unknown:

$18 \%$ / $64 \%$ / $18 \%$

\section{Accident events}

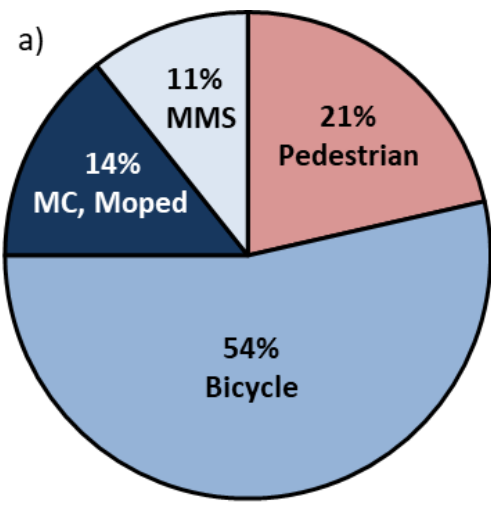

Accident Circumstances

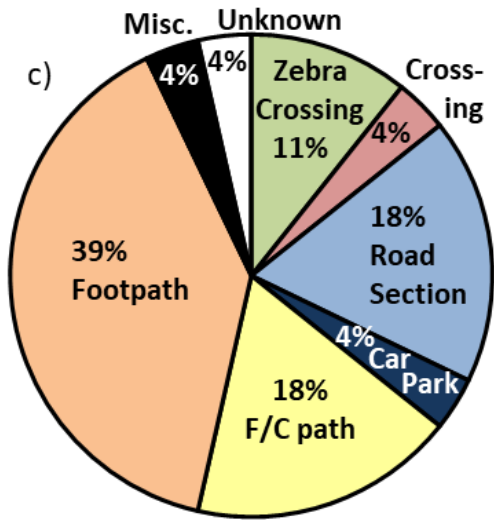

Injury Severity

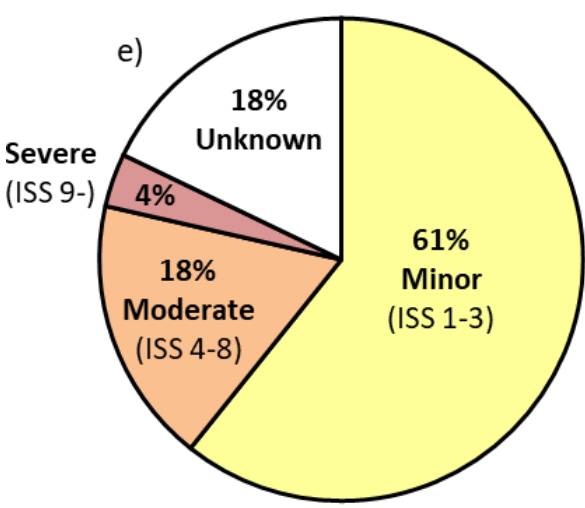

Collisions - Car/Truck/Bus ( $\mathrm{n}=322)$

Males / Females:

$25 \% / 75 \%$

\section{Accident events}

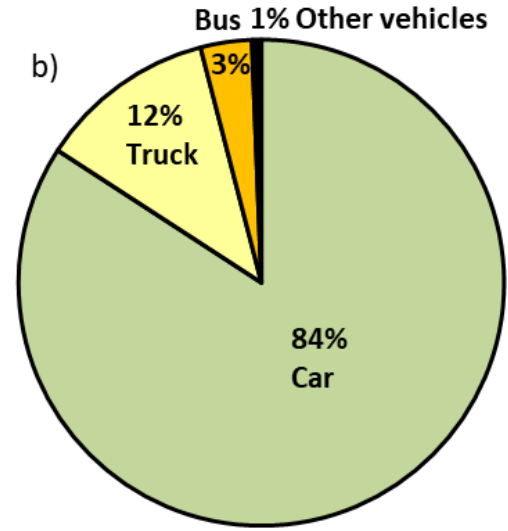

Accident Circumstances

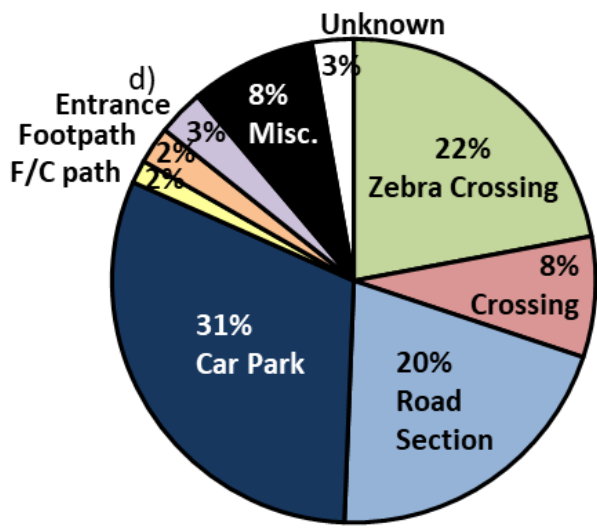

Injury Severity

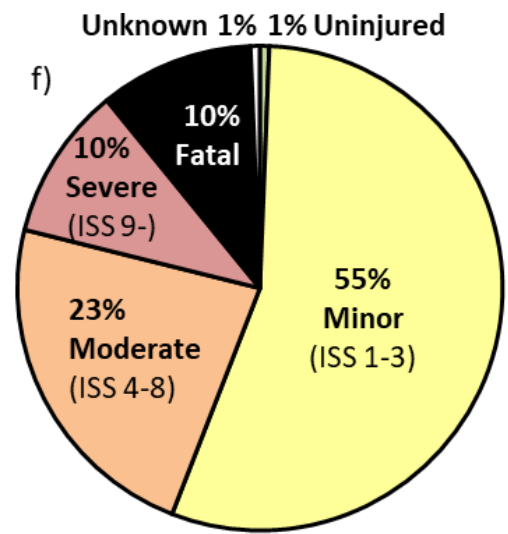

Figure A2. a) VRU and b) car/truck/bus collision accident events; c) VRU and d) car/truck/bus collision accident circumstances; e) VRU and f) car/truck/bus collision accidents injury severity 
Collisions - VRU ( $\mathrm{n}=28)$

Males / Females / Unknown: $18 \%$ / $64 \%$ / $18 \%$

All Reported Injuries $(\mathrm{n}=25)$

[14 cases unknown]

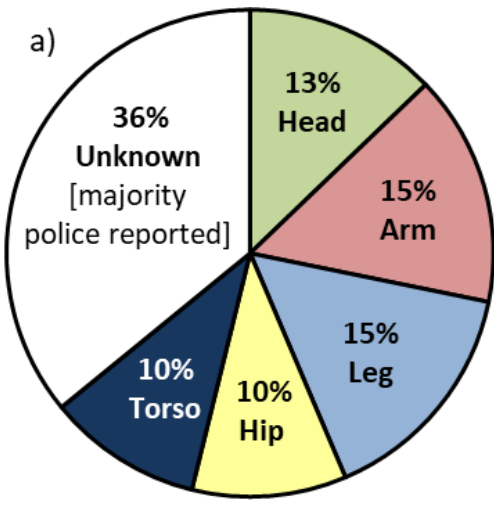

AIS 2+ Injuries ( $\mathrm{n}=6)$

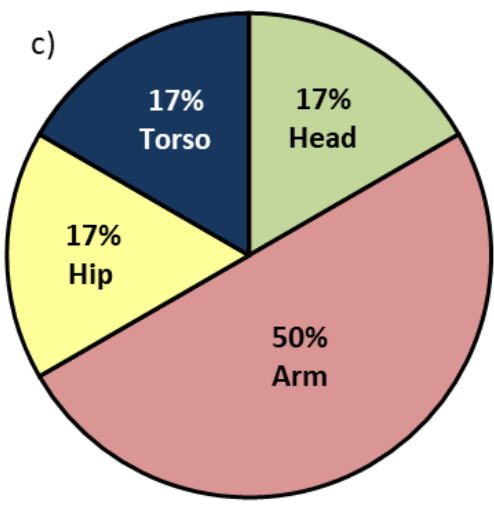

Collisions - Car/Truck/Bus ( $\mathrm{n}=322)$

Males / Females: $25 \% / 75 \%$

All Reported Injuries ( $\mathrm{n}=540)$

[155 cases unknown]

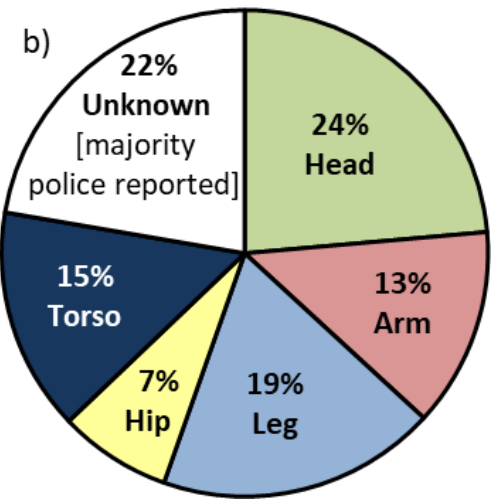

AIS 2+ Injuries (n=286)

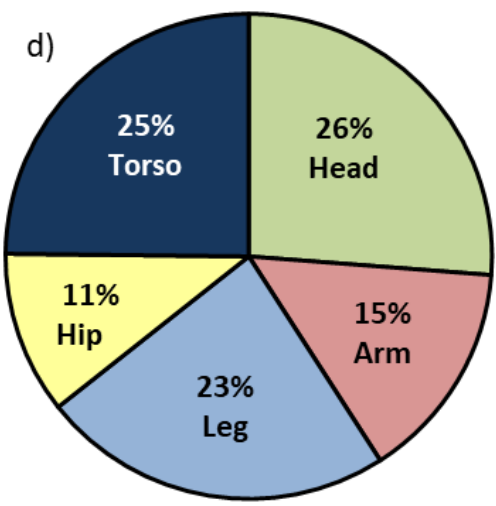

AIS 3+ Injuries $(n=135)$

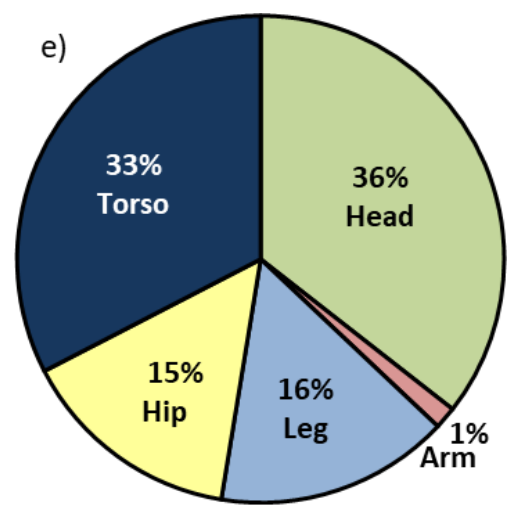

Figure A3. Injured body parts based on: all injuries in a) VRU and b) car/truck/bus collision accidents; AIS 2+ injuries in c) VRU and d) car/truck/bus collision accidents; AIS 3+ injuries in e) car/truck/bus collision accidents 
a)

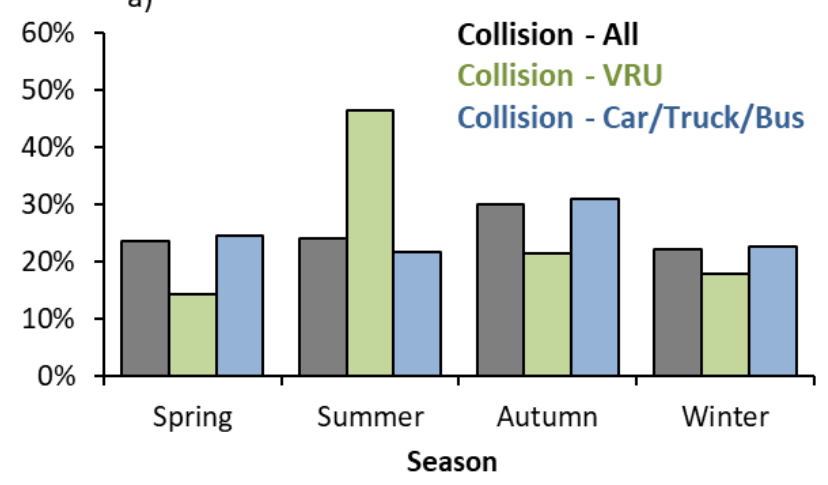

b)

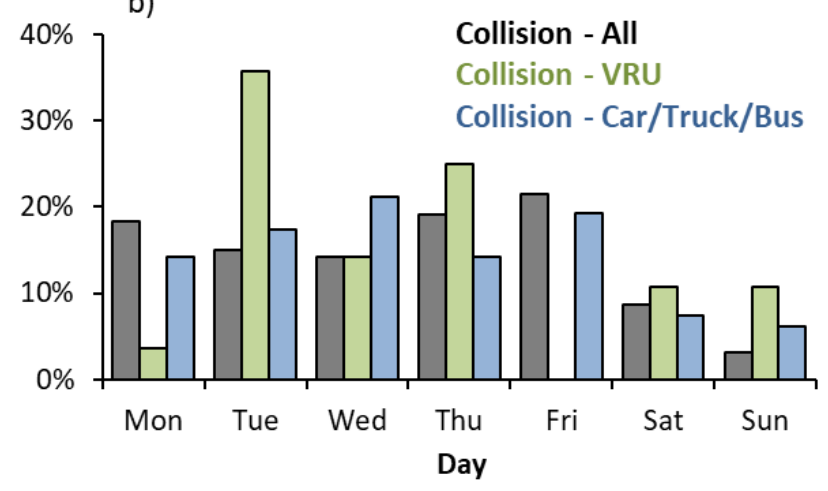

c)

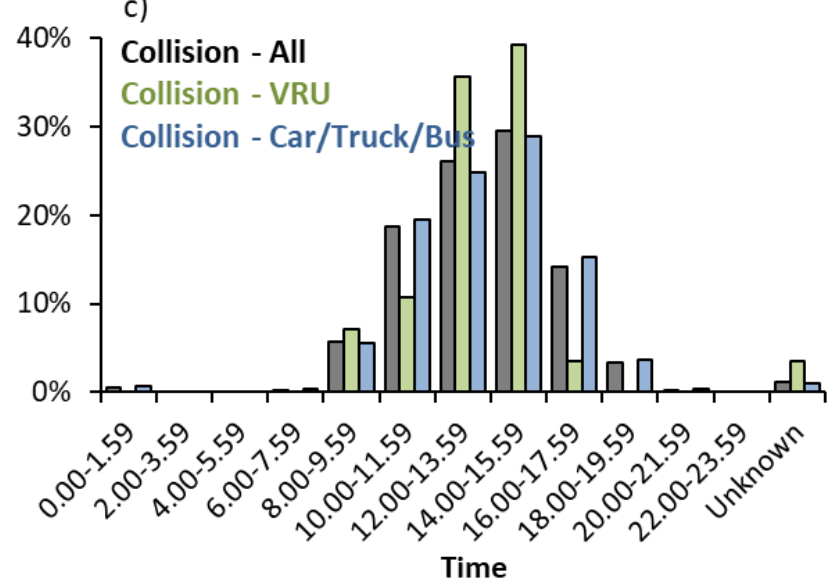

d)

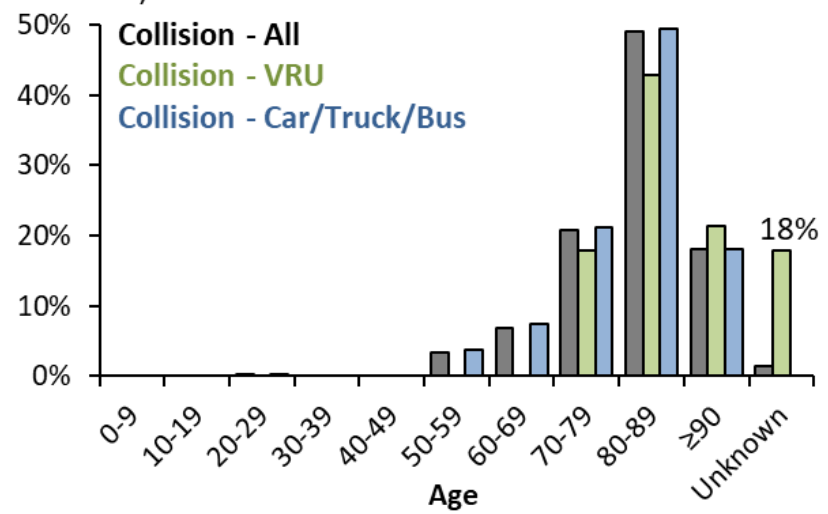

Figure A4. The distribution of a) season, b) day, c) time, and d) age of the driver in powered mobility devices (PMD collisions. Grey bars: all collisions $(n=352)$, green bars: VRU collisions $(n=322)$, blue bars: car/truck/bus collisions $(n=28)$ 